Rapid Reviews COVID-19

\title{
Reviews of "Four Stylized Facts about COVID-19"
}

\section{Gabriele Ciminelli ${ }^{1}$}

${ }^{1}$ Asia School of Business

Published on: Feb 07, 2021

License: Creative Commons Attribution 4.0 International License (CC-BY 4.0). 
To read the original manuscript, click the link above.

Summary of Reviews: Reviewers find that this paper raises important questions about overstating the importance of government-mandated non-pharmaceutical interventions, but that it is undermined by unclear inclusion criteria and overly-broad conclusions that are not all supported by the evidence.

\section{Reviewer 1 |}

\section{Reviewer 2 (Gabriele Ciminelli) | $\square \square \square \square \square$}

\section{RR:C19 Strength of Evidence Scale Key.}

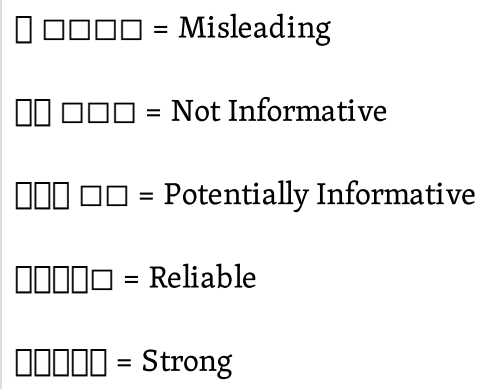

To read the reviews, click the links below. 